Hands-on GPS and Remote Sensing Training for High School Learners During IGARSS 2009 in Cape Town, South Africa.

This is the author's version of the work. It is posted here for your personal use. Not for redistribution. The definitive Version of work was published in the International Geoscience and Remote Sensing Symposium under Institute of Electrical and Electronics Engineers (IEEE).

(C) 2010 IEEE. Personal use of this material is permitted. Permission from IEEE must be obtained for all other uses, in any current or future media, including reprinting/republishing this material for advertising or promotional purposes, creating new collective works, for resale or redistribution to servers or lists, or reuse of any copyrighted component of this work in other works.

L. Hayden, A. Jearld, J. Powell, K. Hayden and N. L. Jackson, "Hands-on GPS and remote sensing training for high school learners during IGARSS 2009 in Cape Town, South Africa," 2010 IEEE International Geoscience and Remote Sensing Symposium, Honolulu, HI, 2010, pp. 1118-1121. doi: 10.1109/IGARSS.2010.5651320

Keywords: Global Positioning System;remote sensing;Global Positioning System; hands-on GPS; remote sensing training; high school learners; IGARSS 2009; South Africa; Geoscience and Remote Sensing Society; IEEE 2009 International Geoscience and Remote Sensing Symposium; conference; Mafeteng Schools Environment Network;Students' Health and Welfare Centres Organization; University of Cape Town; socioeconomically challenged populations; remote sensing art workshop; Mathematics of Remote Sensing team contest; scavenger hunt; National Oceanic and Atmospheric Administration scientists; Earth's systems; Global Positioning System; Remote sensing; Cities and towns; Conferences; Educational institutions; Satellites URL: http://ieeexplore.ieee.org/stamp/stamp.jsp?tp=\&arnumber=5651320\&isnumber $=564880$ $\underline{2}$ 


\title{
Hands-on GPS and Remote Sensing Training for High School Learners During IGARSS 2009 in Cape Town, South Africa
}

\author{
Dr. Linda Hayden, Professor of Computer Science, Elizabeth City State University, NC \\ haydenl@mindspring.com
}
Dr. Ambrose Jearld, Director of Academic Programs, Northeast Fisheries Science Center, NOAA, Woods Hole, MA ambrose.jearld@noaa.gov

Je'aime Powell, GRID Manager and Graduate Researcher, Elizabeth City State University, NC jeaimehp@gmail.com

Kuchumbi Hayden, Network Manager, Elizabeth City State University, NC, khayden5@hotmail.com

Nina L. Jackson, Communication Specialist, National Environmental Satellite, Data \& Information Service, NOAA, Silver Spring, MD nina.jackson@noaa.gov

\begin{abstract}
Continuing the commitment of the Geoscience and Remote Sensing Society (GRSS) to education and outreach, the IEEE 2009 International Geoscience and Remote Sensing Symposium (IGARSS) conference in Cape Town, South Africa provided an opportunity for over 400 local high school students to engage in hands-on GPS training and remote sensing workshops. Mafeteng Schools Environment Network (MSEN) and the Students' Health and Welfare Centres Organization (SHAWCO) worked with the University of Cape Town in identifying the student learners, who had an average age of $\mathbf{1 7 . 7}$ years and came from socio-economically challenged populations in areas surrounding Cape Town. Activities included a remote sensing art workshop, Mathematics of Remote Sensing team contest, and a scavenger hunt requiring students to ask questions of scientists and vendors. NOAA scientists led discussions and demonstrations of educational products to help build understanding of the science of Earth's systems and the stewardship of our planet. This paper details the e-o events and gives demographic information on the participants.
\end{abstract}

\section{INTRODUCTION}

\section{A. Overview}

The IGARSS 2010 organizing committee worked to combine career exploration and direct contacts with scientists to strongly inform, engage and empower young people to think critically, learn, assess, and identify how through remote sensing, they can apply their range of abilities. Online lectures, public tutorials, distinguished speakers and IGARSS tutorials have been pillars of an effective education strategy for the Geoscience and Remote Sensing Society (GRSS). GRSS piloted a new dimension of educational outreach during the 2008 conference in Boston, Mass. [1 3]. The middle school and high school students participating in the IGARSS'08 education and outreach activities described the experience as "life changing"[2]. The IEEE 2009 International
Geoscience and Remote Sensing Symposium (IGARSS) conference in Cape Town, South Africa continued that commitment to education and outreach, with more than double the number of learners participating in the 2009 IGARSS conference compared to previous conferences.

IGARSS 2009 provided an opportunity for more than 400 local high school learners to engage in hands-on GPS training and remote sensing workshops. The average learner was 17.7 years old and came from socio-economically challenged populations from areas surrounding Cape Town.

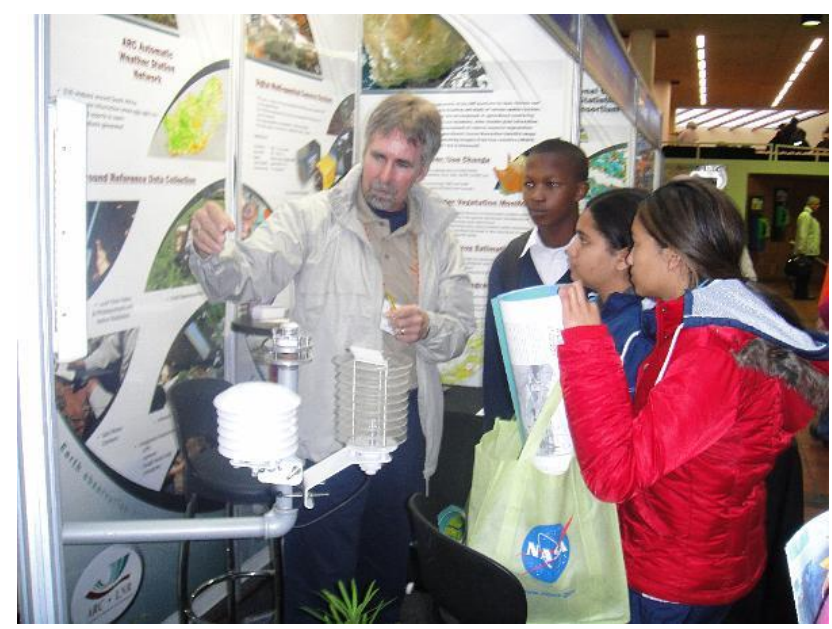

B. Local Support

Two organizations, Mafeteng Schools Environment Network (MSEN) and the Students' Health and Welfare Centres Organization (SHAWCO) assisted the University of Cape Town (UCT) in identifying the student learners. A group of South African teachers decided to form the network, MSEN, believing that rotating leadership would not only help 
motivate participation of other teachers. SHAWCO, the Students' Health and Welfare Centres Organization, is a dynamic, innovative and passionate student-run organization based at UCT. SHAWCO constantly strives to improve the quality of life for individuals in developing communities within the Cape Metropolitan area.

\section{Participants}

SAHWCO has a regular programme of contact with schools in disadvantaged suburbs of Cape Town, focusing on math and science enrichnmment. Some 200 of their scholars were selected to attend the IGARSS 2010 e-o events. The age range of the IGARSS e-o participants is shown in the chart below with the average age being 17.7 years.

\section{A. Age}

Age range of participants

Age ..................... Percent

17 ......................... 50\%

18 …….................. $31 \%$

19 ......................... 7\%

$20 \ldots \ldots \ldots \ldots . . . . . . . . . . . .4 \%$

21 .......................... 2\%

Not declared.......... $6 \%$

\section{B. Student Response}

While participating in the e-o events, most often students inquired about the importance of GIS and remote sensing to Africa and how their communities could be helped. Students reported that the most impressive response to their question was: mapping and protection of the forest, crop growth, prediction of floods and other weather disasters, and crime control.

When asked how they think that remote sensing can empower their community and their life the responses included references to:

Degradation of the environment

Global warming

Location of oil and water resources

Lessen hunger

Farming, land use

Weather, flood damage and disasters

Surveying and building bridges and other structures

Changes in vegetation

Mosquito control

Community preparedness and rescue

Health and AIDS related issues

$$
\text { III. TRAINING }
$$

\section{A. GPS}

The Center of Excellence in Remote Sensing Education and Research (CERSER) supplied the GPS devices for training. The hand-on GPS training at IGASS 2009 utilized Garmin 60 recreational units. The accuracy of measurement is within a tolerance of approximately 15 feet. The GPS 60 unit has one megabyte (MB) of internal memory for storing points of interest, and comes factory preloaded with a worldwide city point database. It is WAAS-enabled for precise location and navigation, and also offers special geocaching features, indoor and outdoor games, an alarm clock, sunrise/sunset and moon phase tables.

During the hands-on GPS workshop, learners received instruction on the types of GPS unit, data collection, analysis and data integration with GIS, and remote sensing use. After receiving instructions on how to operate the devices, students were presented with theoretical challenges of navigating and land surveying. Groups of students then used their hand-held GPS to complete assigned tasks. Each GPS training session was about one hour in length and utilized sites on the campus of the University of Cape Town.

\section{B. IGARSS Scavenger Hunt}

In addition to the GPS and remote sensing workshops, students visited vendor booths and met with scientists. They asked questions and received signatures from the vendors as part of an IGARSS scavenger hunt. Rewards were provided for all who complete the scavenger hunt. Typical questions asked in the exhibit hall included: Why do you enjoy your job? What subjects are most important to study? What is the importance of remote sensing? What is GIS? What is GPS?

\section{Earth System Workshops}

Nina Jackson (National Environmental Satellite, Data \& Information Service) and Ambrose Jearld (National Marine Fisheries Service) of the National Oceanic and Atmospheric Administration (NOAA) conducted discussions and demonstrations of educational products to help build understanding of the science of Earth's systems and the stewardship of our planet. Students learned about satellites, orbits, and sensors by playing games, constructing a mystery book, and making an icosahedrons, fold-up model of the earth as part of hands-on activities related to the use of satellite date in weather and in bathymetric and topographic maps during the NOAA seminars on operational environmental satellites.

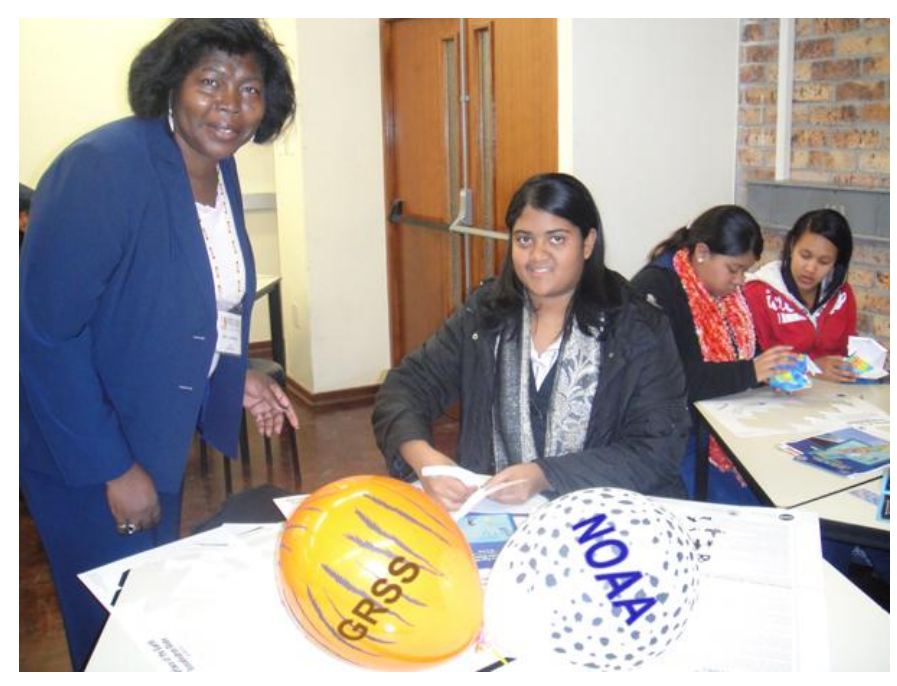




\section{Additional Outreach}

Additional outreach activities included a Remote Sensing Art Workshop and a Mathematics of Remote Sensing Team Contest. For the art contest, students provided a visual insight into how experiences at IGARSS ‘ 09 had impacted them. They were instructed to close their eyes and visualize some of the highlights from their IGARSS experience. They used the images, colors and data from exhibits, meeting with scientists and poster sessions in their design of an IGARSS 2009 computer mouse pad. A special acknowledgement is given to Dr. Anna Martin - Jearld, who used her experience as an elementary school teacher, college professor, counselor and social worked to assist the students with the art contest.

Student teams brought their collective wisdom to the solution of mathematical problems related to remote sensing and

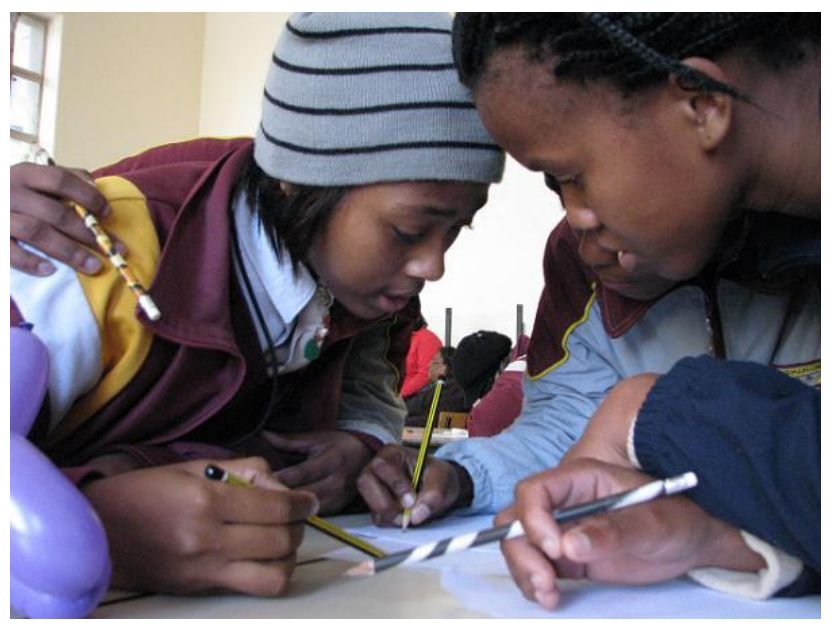

climate change during the team mathematics competition. Teams were challenged to solve 20 multiple choice mathematics questions, written by local teachers to ensure that the African voice was used in phrasing the questions.

Beyond these activities, students also had an opportunity during the conference to view hundreds of research posters related to the development of the African continent or with international relevance. Authors were available to discuss their research and to share their research methods with conference participants.

\section{Conclusion}

The Geoscience and Remote Sensing Society committed to nurturing the Next Generation during IGARSS08 in Boston and continues to look ahead to the future of our field with some fresh approaches as embodied in the IGARSS10 focus on the emerging field of Community Remote Sensing. Appropriately, the IGARSS education and outreach activities continue to take on an increasing level of importance.

\section{REFERENCES}

[1] J. Kereke, E. Miller, IGARSS'08 Boston - "Geoscience and Remote Sensing: The Next Generation", IEEE Geoscience and Remote Sensing Society Newsletter December 2008 cumulative Issue \# 149, ISSN 02746338 Page 21-25

[2] Kunkee, D., "IGARSS'08 Remote Sensing Outreach Program: The Next Generation", IEEE Geoscience and Remote Sensing Society Newsletter December 2008 cumulative Issue \# 149, ISSN 0274-6338 Page 9

[3] D. Kunkee "IGARSS 2008 Brought in The Next Generation", IEEE Geoscience and Remote Sensing Society Newsletter September 2008 cumulative Issue \# 148, ISSN 0274-6338 Page 9 